Submission to Academia Letters

\title{
Urbanised Coffee; A Strategic Plan for the Spe- cialty Coffee Hub in the United Arab Emirates
}

Kurniawan Arif Maspul, University of the People

\section{Specialty Coffee Market in the United Arab Emirates}

UAE is undoubtedly becoming a mecca for specialty coffee culture in the Middle East region. With the unprecedented growing demand for specialty coffee, the GCC region and Dubai in particular has seen rapid growth in local and

foreign investments in various business models within the market and swiftly became a hub for the coffee industry in the past 5 years (Maspul, 2021a). This significant cultural shift in MENA has seen a considerable increase in consumption of specialty coffee, with sales growing twice as fast as the global average (Comunicafe, 2019). By 2021, the coffee industry in the Middle East is expected to grow to $\$ 44$ billion, according to Euromonitor International.

With the pandemic bringing historic changes to the socio-economic situation in the world, the coffee industry in UAE has shown high adaptability to the new challenges as demand went into e-commerce. In 2020, the e-commerce market in UAE for coffee hit a record $\$ 3.9$ billion - a strong increase of $53 \%$ and constituted an impressive $8 \%$ of the total retail market share, according to Dubai Media Office (Dubai Media Office, 2021). This proves the customer loyalty and strong purchasing preferences of the UAE coffee consumer.

Meanwhile, the specialty coffee community continued its consistent growth among both, local and ex-pat communities. As the public is getting informed and enthused by the art and culture of specialty coffee, the increasing sales of various machines and accessories for brewing confirm that this trend isn't going anywhere. Specialty coffee has become a staple in the modern lifestyle as an anchor in terms of remote work or social setting, hobby, or cultural pastime (Maspul, 2021b). As UAE specialty coffee community growth continues

Academia Letters preprint.

(O)2021 by the author - Open Access - Distributed under CC BY 4.0 
impressing the world with its consistent and rapid growth, Specialty Coffee Association announced the World of Coffee 2022 to be hosted in Dubai (Specialty Coffee Association, 2021). This will provide a historic opportunity for homegrown brands in the region to position themselves as a global player in the specialty coffee market.

The establishment of the DMCC Coffee Center is another strong indicator and facilitator of specialty coffee market growth in the region. As a government incentive program for the growth of the specialty coffee sector, it includes a stateof-the-art coffee academy and various innovation programs to further the science and skill of specialty brewing. This shows further opportunities in research and development of niche specialty coffee production as well as new business models, a unique possibility of development of lucrative innovative solutions within this booming sector.

Within the specialty coffee industry, the roastery holds a key role in market positioning. Whether it's a B2C or B2B model, the average order value will be heavily based on the art of roasting. Even though UAE roasteries often appear in the analysis of international coffee communities, currently, coffee roasters in America and Europe dictate $70 \%$ of the final selling price for specialty coffee products in the world (Mordor Intelligence, 2021; 6Wresearch, 2021). Given the dynamic growth of the specialty community in the MENA region, changing global environment and UAE's hands-on incentives in furthering the industry and innovation within it, there is the potential of a power-shift, when it comes to price positioning, among the specialty coffee roasting services that will drive the margins higher.

\section{Core Values and Market Positioning}

As the consumers are well-versed in the specialty coffee industry, there are certain core value points and business practices that cannot be compromised as they will affect the desirability of the brand.

- Urbanised Coffee brand must establish itself and remain a sustainable specialty coffee value chain from farm to cup.

- Consistency of taste and quality of the specialty coffee menu items must be a staple of Urbanised Coffee, which can be reached through skilled sourcing/logistical solutions and establishment of exceptional roasting/brewing standards within the brand.

Academia Letters preprint.

(O)2021 by the author - Open Access - Distributed under CC BY 4.0 
- High quality and fresh specialty coffee roasting must be at the core of Urbanised Coffee brand's B2C and B2B operations

- As the art of specialty coffee requires mastery of skills, the emphasis on experienced, enthusiastic and SCA certified staff must be a staple of Urbanised Coffee.

\section{Potential Revenue Streams}

Diversification of revenue streams without compromising the above-mentioned core values of Urbanised Coffee will reduce risks in the start-up phase and increase organic growth opportunities:

- Direct customer sales of specialty coffee menu as well as pastry items made fresh by Urbanised's own pastry chef.

- Urbanised's roastery offering B2B beans and pastry sales to local F\&B outlets

- E-commerce sales (wholesale and individual sales) through a modern web and social media outlet.

- Through the next two years, Urbanised will develop its outlets and create opportunities for the global community to build and develop specialty coffee knowledge through the coffee value chain in Urbanised Coffee.

- Coffee Subscription: In addition to selling roasted coffee beans (250gr and $1 \mathrm{~kg}$ size) for individuals through retail and wholesale, Urbanised can make weekly/monthly subscriptions for consumer needs used by the subscription package delivered fresh to their doorstep.

- Coffee Hub and Event Hosting: Besides providing intensive courses through the Specialty Coffee Association program, Urbanised Coffee can give regional hub and global coffee events. In addition to strengthening branding, it will also offer a strong diversification in understanding local and global consumers.

- Upon establishment of a strong brand and operations, Urbanised Coffee can offer franchise opportunities to retailers globally.

\section{Brand Risk Analysis}

Based on the expertise of the specialty coffee community insiders, the most common mistakes and risks observed de-facto among businesses that had a direct effect on bottom lines and growth rates.

1. Unfit or Dysfunctional Team

The most common and hard-hitting factor among new specialty coffee outlets

Academia Letters preprint.

(C2021 by the author - Open Access - Distributed under CC BY 4.0 
is ineffective team dynamic or unfit team members. The first years of building a brand in an up-and-coming industry within unprecedented market conditions are crucial to the successful growth and maturing of the business. With that in mind, engaging a team that doesn't have effective internal communication and/or that requires micro-management will hit the overall customer experience and quality of service.

\section{Attempting to Grow Too Quickly}

Despite the growing demand, any business outlet in a metropolitan setting will be faced with serious competition. In an attempt to "win the race", specialty coffee shops frequently attempt scaling while the operations and brand identity have not, yet, gained proper foundation and recognition among the customer base. The average customer of the specialty coffee market is well-formed in their preferences and have high standards of overall customer experience. If a compromise is made anywhere in the quality and values of the brand in order to increase revenues - there will be an immediate negative shift in the loyal customer base.

\section{Inconsistency in Quality of Menu Items}

The specialty coffee industry at its core is a premium consumer market, where the brand is built on consistency of sustainably sourced and beautifully served rich flavour. The specialty coffee experience is frequently a therapeutic and self-indulgent artisanal experience that the average customer is willing to pay a premium price as a refuge and culinary treat. One poor experience is enough for the customer to reconsider and start shopping for comparable substitutes at other specialty coffee outlets.

\section{Inconsistency in Customer Care}

As specialty coffee has become a staple of the modern lifestyle, it must live up to the expectations of a premium service that comes with it. The experience of indulgence in an artfully prepared cup of coffee can be completely overwhelmed by sub-par customer service. When the service does not match the craftsmanship of the coffee - the impression of the taste gets affected, as well. Customer care is often overlooked as secondary in the list of priorities, while in fact, it should be another element that elevates and emphasizes the specialty coffee experience.

5. Unclear Policies and Standards

Academia Letters preprint.

(O2021 by the author - Open Access - Distributed under CC BY 4.0 
In day-to-day operations, the occurrence of occasional complaints or conflicts of interest are inevitable, and they can arise from both individual and business customers. When standards and policies are unclear and not defined with precision, these can trigger stressful and brand-affecting situations for the staff and the customer. Most start-up specialty coffee brands do not prioritize the development of operational policies and standards manuals, which in turn leads to bad experiences that could have been prevented.

6. Understaffing or Overstaffing

Steaming from ineffective operations planning and team management is the problem of understaffing or overstaffing. Each in its own way affects the customer experience through the quality of menu and service and can have a disastrous effect on the brand. It also leads to high staff turnover, which ends up negatively affecting the quality standards as well as is a heavy cost burden long-term.

\section{Risk Management Solutions}

1. The Team (Strategically coordinated and timely recruitment, proper training, and skilled management of a dynamic team)

According to the latest findings, the following characteristics of a startup team heavily affect the survival and growth of a business model within the context of the modern-day industry environment: commitment, ownership, communication, expertise/mastery within the focus area, expertise in business/administration, network/insider contacts, stress coping, coherency. These factors must be considered and probed during the interview process. The overall team cumulatively and, if possible, individually must score high on as many of these as possible.

At the same time, common characteristics that have a negative impact on start-up team dynamic should be taken into consideration during the interview process and, where possible, avoided or reduced in the overall team score count: third-party needs, vulnerability, and the illusion of control. The last one refers to the mindset of narrow expectations, which in turn results in poor adaptability and trouble-shooting skills. The team needs to be able to overcome unexpected barriers with creative troubleshooting and, in case of failures, fail fast and effectively to mould the operations to the needs of the market without compromising set values or losing motivation.

Academia Letters preprint.

(O)2021 by the author - Open Access - Distributed under CC BY 4.0 
To engage individuals that have the required skill set, it is essential to put together an attractive compensation package that will attract and retain highly skilled team members, who are up to the task of building a specialty coffee brand and experience. The team must be allowed adequate time to train and develop meaningful operational practices. Though it may seem costly, this investment will be the most cost-effective solution long term.

2. The Vision (Consistent adherence to values and brand vision set as a priority over compromising growth)

In the uncertain start-up phase, clearly defined values and vision are the best tool, which will navigate the decision-making in the right direction and allow for flexibility/adaptability in a new business environment. This gives the team an anchoring point with which choices and decisions can be assessed and, hence, avoiding incoherent operations and internal team conflicts in the early stages of business establishment.

3. The Standards (Effective implementation of defined and coherent policies and standards)

A delicate balance must be reached between the flexibility to adapt in the early stages and the establishment of a firm foundation for the future growth of the brand. To achieve that balance, policies and standards must rely upon meaningful operational goals for the team as a whole and each member of the team individually. As the above-mentioned solutions to the most common risks are implemented, the competent and motivated staff, driven by defined common values, will be able to build a strong operational structure and policy manual, guided by meaning rather than instructions and micro-management.

\section{Five Year Goals}

Below are the overall business goals set for Urbanised Coffee in the first five years of operations:

First-quarter of 2022

1. Urbanised Coffee can open sales through roasted coffee production in associated businesses and other business places (hotels, lounges, and coffee shops), making Urbanised the best choice for the coffee value chain.

2. This achievement can be assisted by digital marketing sales that can drive consumers to access purchases through web-based e-commerce. In addition, with e-commerce, unlimited access to deals can be boosted to the local and the

Academia Letters preprint.

(O2021 by the author - Open Access - Distributed under CC BY 4.0 
global markets.

3. Likewise, outlets that are the centre of coffee value chain turnover will physically strengthen branding locally.

4. Strengthening coffee knowledge in local and global coffee communities with a coffee academy based on the curriculum from the Coffee Diploma in the Specialty Coffee Association's Coffee Skills and Sustainability Program.

5. Growing sales at Urbanised Coffee (outlet) per day AED 15,000 for only coffee drinks.

Year One and Two (2022 - 2023)

1. Urbanised Coffee can strengthen local branding by opening additional strategic outlets located in the middle of the business district in Dubai and Abu Dhabi.

2. Urbanised Coffee helps fulfil caffeine needs for consumers in busy areas by using bar stalls (pop-up bars) at several super active spots in Dubai.

3. Associate with the Specialty Coffee Association and the Coffee Quality Institute to make Urbanised Coffee a Certified Coffee Campus (SCA Premier Campus) in the United Arab Emirates.

4. Making Urbanised Coffee Academy a hub for roasters, baristas and coffee professionals seeking professional coffee certification, which was initiated by themselves.

5. Obtain a license as a Coffee Institute from the local accreditation body (Ministry of Higher Education) for the Diploma for Coffee Professional program.

6. Providing a postgraduate degree (hybrid e-learning) for CAS (Certificate for Advanced Studies) in Coffee Excellence in collaboration with Zurich University for Applied Science Switzerland.

7. Opening local and regional competitions in introducing Urbanised Coffee as a local brand that has world-class values.

Year Three and Four (2023 - 2024)

1. Making Urbanised a massive production company that meets the needs of the local and global coffee market by using a high-end roasting machine (Loring $35 \mathrm{~kg}$ ) to help ensure consistency in large productions.

2. Targeting the production of one ton per month for supply coffee.

3. Making Urbanised a green coffee sourcing hub for the Middle East and the global coffee market.

Academia Letters preprint.

(O)2021 by the author - Open Access - Distributed under CC BY 4.0 
4. Making Urbanised Coffee a global hub for research and project development through sustainability programs.

5. Opening Urbanised Coffee at GCC through a partnership concept to Coffeepreuners with core values owned by Urbanised Coffee.

Year Four and Five (2024-2025)

1. Maintaining sales from the previous years, increasing the partnership and collaboration with regional and global coffee businesses.

2. Offering Urbanised Coffee partnership to Asian and European markets with Dubai branding as Urbanised Coffee HQ.

3. Making Urbanised Coffee a sustainable consulting project for the coffee business at GCC and globally.

Urbanised Coffee is expected to grow at the beginning of the business by planning deeply in every related part from budgeting to human resources and each role.

Academia Letters preprint.

(O2021 by the author - Open Access - Distributed under CC BY 4.0 


\section{References}

Bellwether Coffee. (2021, February 12). Why Coffee Shops Should Start Roasting Coffee In-House. Bellwether Coffee. https://www.bellwethercoffee.com/ why-coffee-shops-should-start-roasting-coffee-in-house/

Comunicaffe. (2019, October 31). Coffee Industry in the Middle East to reach a value of $\$ 44$ billion by 2021. Comunicaffe. https://www.comunicaffe.com/ coffee-industry-in-the-middle-east-to-reach-a-value-of-44-billion-by-2021/

Dubai Media Office. (2021, June 23). Value of UAE Retail e-Commerce Market Hit Record \$3.9 Billion in 2020: analysis. Media Office. https://www. mediaoffice.ae/en/news/2021/June/23-06/Dubai-Chamber

Maspul, K. A. (2021a) The Role of Instagram in Specialty Coffee Marketing during the Pandemic in the United Arab Emirates. Academia Letters. https://doi.org/10.20935/AL3602

Maspul, K. A. (2021b). Specialty Coffee Trends Post-Lockdown in the United Arab Emirates. Academia Letters. https://doi.org/10.20935/AL3185

Maspul, K. A. (2021c). Correlation between Cropster and Sustainability of Coffee Roasteries in The United Arab Emirates 2021. Journal of Economics and Development, 1(1), 14-30.

Mordor Intelligence. (2021). Middle East \& Africa Coffee Market - Growth, Trends, COVID-19 Impact, and Forecasts (2021 - 2026). Mordor Intelligence. https://www.mordorintelligence.com/industry-reports/middle-eastafrica-coffee-market

6Wresearch. (2021). UAE Coffee Market (2020-2026). 6Wresearch. https:// www.6wresearch.com/industry-report/uae-coffee-market-2020-2026

Specialty Coffee Association. (2021, November 4). World of Coffee, SCA'S Premier Coffee Trade Show, Expands to the Middle East in 2022. Specialty Coffee Association. https://sca.coffee/sca-news/world-of-coffee-expands-tothe-middle-east-in-2022

Academia Letters preprint.

(C2021 by the author - Open Access - Distributed under CC BY 4.0 